\title{
PAISAGEM URBANA PARQUE DO POVO - PRESIDENTE PRUDENTE
}

Yeda Ruiz Maria, Sibila Corral de Arêa Leão Honda, Vitor Ruiz Menezes.

Universidade do Oeste Paulista - UNOESTE, Curso de Arquitetura, Presidente Prudente, SP. E-mail: yedarm@hotmail.com

\section{RESUMO}

A paisagem urbana tem sido concebida durante muito tempo por modelos que não se conversam, fazendo com que um se sobressaia sobre o outro, deixando de lado a cidade segura, sustentável e viva que são fatores para a qualidade de vida na cidade, a dimensão humana e a inserção do planejamento urbano ambiental nos planos diretores das cidades. Esse projeto tem como objetivo analisar as atuais condições do Parque do Povo de Presidente Prudente, no Estado de São Paulo, afim de apresentar uma nova proposta, mantendo o equilíbrio entre cidade, pessoas e natureza. A metodologia a ser seguida está baseada na investigação bibliográfica, levantamentos métricos, fotográficos e mapeamentos.

Palavras-chave: Qualidade de Vida, Paisagem Urbana, Dimensão Humana, Planejamento Ambiental, Urbanismo.

\section{URBAN LANDSCAPE PARQUE DO POVO - PRESIDENTE PRUDENTE}

\section{ABSTRACT}

The urban landscape has been designed for a long time for models that do not talk, causing one stands out over the other, leaving aside the safe, sustainable and living city that are factors for the quality of life in the city, the human dimension and the inclusion of environmental urban planning in master plans of cities. This project aims to analyze the current conditions of Presidente Prudente People's Park in the State of São Paulo, in order to present a new proposal, maintaining the balance between city people and nature. The methodology to be followed is based on bibliographical research, metric surveys, photographic and mapping.

Keywords: Quality of Life, Townscape, Human Dimension, Environmental Planning, Urbanism. 


\section{INTRODUÇÃO E JUSTIFICATIVA}

A partir dessas análises preliminares, verifica-se importante analisar parques e praças urbanas existentes. Nesse sentido, esta pesquisa foca na área do Parque do Povo que surgiu da urbanização e expansão da cidade de Presidente Prudente interior de São Paulo.

O estudo apontado visa identificar a importância dos parques urbanos que auxiliará em posterior trabalho projetual de revitalização da paisagem para se enquadrar nas características de parque urbano. Parte-se da hipótese de que o Parque do Povo apresenta deficiência na prestação de serviços, em sua paisagem, embora seja identificado como símbolo urbano.

O Parque do Povo foi projetado a partir da possibilidade de aproveitamento de fundo de vale que cortava a malha urbana de Presidente Prudente, após processo de canalização do Córrego do Veado, proporcionando lazer em áreas verdes para a população municipal. Por ter sido projetado apoiado na canalização e cobertura de um córrego urbano, quais seriam as características legais e urbanísticas para esse parque? Como se entende a paisagem produzida pelo parque?

O objetivo geral deste trabalho foi analisar as atuais condições do Parque do Povo no município de Presidente Prudente, e estabelecer parâmetros e diretrizes projetuais para uma nova proposta de paisagem urbana, para que se tenha um Parque que respeite o planejamento urbano ambiental, a qualidade de vida e a dimensão humana.

Nesta proposta, optou-se pelo desenvolvimento do tema por meio de investigação bibliográfica e análise de caso com levantamentos métricos e fotográficos, assim como mapeamentos. Quanto à pesquisa, foram examinados livros, artigos e materiais disponibilizados na internet, a fim de produzir uma teorização sobre o assunto tratado.

\section{METODOLOGIA}

Nesta proposta, optou-se pelo desenvolvimento do tema por meio de investigação bibliográfica e análise de casos. Quanto à pesquisa foram examinados livros, artigos e materiais disponibilizados na internet, a fim de produzir uma teorização embasada na literatura científica. No que se refere à análise de casos, foram escolhidos para objeto de estudo o parque do povo situado na cidade de Presidente Prudente-SP, sendo analisado com levantamentos métricos e fotográficos e mapeamentos.

\section{RESULTADOS}

Os espaços públicos, em modo geral, são negligenciados pelos gestores, uma vez que não recebem a devida atenção que deveriam receber. Tais espaços, como o Parque do Povo, apenas serviram para aquisição de poder através da paisagem, quando se tinha um espaço diagnosticado como um problema para a malha urbana, no qual impediria sua expansão, pois esse mesmo espaço abriga um córrego, entendido como umas das principais barreiras.

Fica claro que a falta de análises e estudos para a implantação do Parque do Povo levou-o a uma implantação deficitária, uma vez que não atende qualitativamente a dimensão humana, entendida aqui como o pedestrianismo.

\section{DISCUSSÃO}

Foi a partir da revolução industrial, séc. XX, que a natureza foi submetida a valores de capital, originando transformações nos territórios das cidades e na percepção do homem com o meio natural. Responsável pelo rompimento da natureza com a malha urbanizada, levando as pessoas para um pensamento de inesgotabilidade dos recursos naturais, sem pensar nos impactos ambientais que toda essa ação geraria para o desenvolvimento urbano e qualidade de vida. 
(Franco, 2001).

Surge então a necessidade de um repensar a paisagem da cidade, visando a qualidade de vida dos habitantes, que segundo uma nota da Organização das Nações Unidas (ONU) discutida por Amanda Marton no site ArchDaily no dia 17 de maio de 2016, existe um alerta sobre a diminuição dos espaços públicos nas cidades, entendidos por eles como "lugares de propriedade público ou de uso público, acessíveis e agradáveis para todos de forma gratuita e sem intenção de lucro, o que inclui as ruas, espaços abertos e instalações públicas", e fortificam ainda a ideia de espaços pensados e projetados para os pedestres, no qual estudos mostram que apenas $21 \%$ da superfície terrestre é ocupada por espaços públicos no mundo, e apenas $37 \%$ desses espaços são desenvolvidos com planos urbanísticos.

Gehl (2015) diz que nesse processo de planejamento, a dimensão humana é um tópico esquecido, característica reforçada pelo estilo modernista onde os espaços públicos, áreas de pedestres e parques recebem baixa prioridade em quanto o tráfego de automóveis ganham cada vez mais força.

Os parques urbanos são ambientes de grande utilidade para a população, embora, em muitos casos, sejam locais de implantação deficitária ou com carência de real uso social.

\section{CONSIDERAÇÕES FINAIS}

O parque acaba não sendo usufruído por completo, pois seus recursos naturais foram agredidos de forma negligente, quando o córrego passa a ser canalizado e some por inteiro da paisagem, sendo que, na verdade, deveria ser partido para a idealização do parque.

Dessa forma, diante destas limitações impostas pela forma incorreta de idealização do parque, busca-se, neste trabalho, apoiado no Planejamento Ambiental, diretrizes para melhor atender a qualidade do espaço do Parque do Povo; pois uma vez que esse espaço for analisado e reformulado mediante o Planejamento Ambiental, apoiar-se-á nos caminhos da sustentabilidade e da conscientização ao conservação do meio ambiente, ao reatar a natureza em meio à malha urbana densa, como ocorre no Parque do Povo.

$\mathrm{Na}$ análise da Paisagem Urbana, foi necessário estabelecer o ritmo lento, discutido aqui como fator principal para manter uma cidade viva, segura e sustentável, oferecendo espaços de qualidade para a permanência, sem vias de transito rápido, fazendo essa quebra de paradigma estabelecido pelo período modernista na priorização aos automóveis.

A inter-relação de Planejamento Urbano Ambiental, Sustentabilidade, Qualidade Ambiental, Qualidade de Vida e Dimensão humana, são vários elementos que qualificarão o parque, possibilitando uma análise estratégica para a futura intervenção.

\section{REFERÊNCIAS}

ABBUD, B. Criando paisagens: guia de trabalho em arquitetura paisagística. 1. Ed. São Paulo: Senac, 2006.

CULLEN, G. Paisagem urbana. 1. Ed. Portugal: Edições70-Brasil, 2006.

FRANCO, M.A.R. Planejamento ambiental para a cidade sustentável. 2. Ed. São Paulo: Annablume, 2001.

GEHL, J. Cidade para pessoas. 3. Ed. São Paulo: Perspectiva S.A, 2015.

JACOBS, J. Morte e vida de grandes cidades. 3. Ed. São Paulo: vmf martinsfontes, 2014.

LERNER, J. Acupuntura urbana. 5. Ed. Rio de Janeiro: Record, 2011. 
ALBANO, M.P. A importância do planejamento urbano ambiental - a habitação social e a expansão urbana em Presidente Prudente - SP. 2013. 80 f. Dissertação (Mestrado e Meio Ambiente e Desenvolvimento Regional) - Universidade do Oeste Paulista, UNOESTE, Presidente Prudente - SP.

BORTOLO, C.A. O espaço público e a dinâmica da produção das cidades: uma análise sobre o parque do povo em Presidente Prudente - SP. In: I Simpósio de estudos urbanos: Desenvolvimento regional e dinâmicas ambientais, 2011.

BORTOLO, C.A. O espaço público do parque do povo - Presidente Prudente - SP: reflexões geográficas. Revista Geografia em Atos, Presidente Prudente, v. 1, n. 13, p. 50-65, jan./ jun. 2013.

GOMES. L. ; ENCENHA. M. R. ; ALBANO. M. P. ; MARIA. Y. R. Crescimento urbano e consequentes inundações na cidade de Presidente Prudente: estudo de caso Parque do Povo. Presidente Prudente: Universidade do Oeste Paulista, UNOESTE, 2013.

GUIMARÃES, E.A. Parques lineares como agenciadores de paisagem: realidades e possibilidades do rio tubarão no contexto urbano de tubarão, SC. 2011. 255 f. Dissertação (Mestrado em Urbanismo, História e Arquitetura da cidade) - Universidade Federal de Santa Catarina, UFSC, Santa Catarina SC.

HONDA, S.C.A.L. Habitação de baixa renda como produto do capital: o programa de arrendamento residencial (PAR) em Presidente Prudente - SP. 2011. 205 f. Tese (Doutorado em Arquitetura e Urbanismo) - Universidade Presbiteriana Mackenzie, UPM, São Paulo - SP.

SCHÜTZER, K. A percepção do pedestre sobre a qualidade da paisagem urbana. 2011. $79 \mathrm{f}$. Dissertação (Mestrado em Engenharia Urbana) - Universidade Federal de São Carlos, UFSCAR, São Carlos - SP.

VALENTINE, S.M.R. Os sentidos da paisagem. 2012. $310 \mathrm{f}$. Tese (Doutorado em Arquitetura e Urbanismo) - Universidade de São Paulo, FAU-USP, São Paulo- SP.

AMBIO - Associação Brasileira de Biossegurança. A paisagem como um dos elementos essenciais a qualidade de vida. Disponível em: <http://www.anbio.org.br/site/index.php?option=com content\&view=article\&id=464:a-paisagemcomo-um-dos-elementos-essenciais-a-qualidade-de-vida\&catid=66:biodiversidade\&ltemid=61>.

Acesso em: 04 maio. 2016.

IBGE - Instituto Brasileiro de Geografia e Estatísticas. Dados gerais do município de Presidente Prudente - SP. Disponível em: < http://cidades.ibge.gov.br/xtras/perfil.php?codmun=354140>. Acesso em: 18 abr. 2016.

IBAMA - Instituto Brasileiro do Meio Ambiente e dos Recursos Naturais Renováveis. Qualidade ambiental: reflexões sobre o conceito. Disponível em: < http://www.ibama.gov.br/phocadownload/sala_de_imprensa/revistaeletronicaedicao1.pdf>. Acesso em: 22 abr. 2016.

PRESIDENTE PRUDENTE. Decreto de Lei n.o 153, de 10 de janeiro de 2008. Dispõe sobre a Lei de Zoneamento do Uso e Ocupação do Solo, da Área Urbana do Município de Presidente Prudente e 
dá outras providenciais. Lei de Zoneamento Urbano, Presidente Prudente, SP, 10 de jan. de 2008. Disponível em: < http://www.presidenteprudente.sp.gov.br/site/Documento.do?cod=612>. Acesso em: 03 abr. 2016.

MMA - Ministério do Meio Ambiente. Agenda 21 (Rio 92). Disponível em: < http://www.mma.gov.br/responsabilidade-socioambiental/agenda-21/agenda-21-global>. Acesso em: 23 abr. 2016. 